\title{
Comprehensible Technique in Solving Consecutive Number Problems in Algebra
}

\author{
Gener Santiago Subia \\ Graduate School, Nueva Ecija University of Science and Technology, Cabanatuan City, Philippines \\ Email: subiagener@yahoo.com
}

How to cite this paper: Subia, G.S. (2018) Comprehensible Technique in Solving Consecutive Number Problems in Algebra. Jour nal of Applied Mathematics and Physics, 6, 447-457.

https://doi.org/10.4236/jamp.2018.63041

Received: January 31, 2018

Accepted: March 5, 2018

Published: March 8, 2018

Copyright (c) 2018 by author and Scientific Research Publishing Inc. This work is licensed under the Creative Commons Attribution International License (CC BY 4.0).

http://creativecommons.org/licenses/by/4.0/

(c) (i) Open Access

\begin{abstract}
This research paper evaluated and investigated the effectiveness of the comprehensible technique (CT) introduced by the researcher as an alternative solution to Algebra's linear equations in solving consecutive number problems. The CT is a proposed easy and efficient way of solving number problems which aimed to help the learners reduce their difficulties in using variables since the technique only uses basic arithmetic and mental Mathematics. Evaluation research was utilized in this study where 20 people, from various ages and professions, were chosen purposively as respondents of the study. The study found out that CT was very effective for the respondents especially in unlocking difficulties in solving consecutive number problems. Moreover, according to them, the $\mathrm{CT}$ is easy to use, it is engaging and enjoyable, direct and simple and can be utilized as shortcut way of solving consecutive number problems when competing in Math quiz bees or taking board examinations where time is of the essence.
\end{abstract}

\section{Keywords}

Algebra, Comprehensible Technique, Consecutive Number Problems, Linear Equation

\section{Introduction}

Teaching is both science and an art employing strategies, schemes or tactics to achieving a goal. Strategies, to be useful, require intelligence, maturity and devotion of teachers. Furthermore, successful teachers should have the knowledge and the sense of purpose that allows them to rise above casual or conventional approaches and to do things others cannot [1].

According to the author in [2], teachers should be creative in their thinking and in their approach. An innovative educator is very uncomfortable with doing 
business as usual, especially when it yields no result. So, they go to work brainstorming ways to make things better. They may change up a lesson to make it more engaging or increase student motivation.

The author in [3] stated that if my students cannot understand and remember through the way I teach (method A), and I must give up A for an innovative teaching method $\mathrm{B}$.

Innovative teaching is needed in subjects such as Algebra where the students have negative attitudes towards it. According to [4], teaching of Algebra is difficult and always will be. Some of the identified factors contributed to its difficulty are its non-visual nature, apparently arbitrary nature and the relationship between symbolism (variables), system and question.

For students to understand Algebra, the author in [5] asserted that teachers need to try and give useful and helpful explanations and need to be aware of as many typical understandings and confusions. He also added that one does not necessarily need to solve Algebra problems in an "algebraic way" since the idea in real life is to solve problems however an individual can.

This is also the realization of the researcher who is teaching Algebra for more than 10 years. Although rules in solving problems should be followed by students, as an innovative teacher, he believes that alternative solutions for those complex problems should be introduced as part of innovative teaching. Innovative teaching is necessary to help students to reach their full potential. Higher educational institutions, through the teachers, should serve the long term intellectual needs of students by providing new material by which helps the student to gain new insights or open up new channels of intellectual stimulation or enhance student's essential and creative thinking power. Innovative teaching is a necessity for all teachers in order to meet the educational needs of the new generations, however, some research points out that many teachers lack competencies for innovative teaching [6].

Based on the above scenario, this study looked into the effectiveness of the comprehensible technique (CT) introduced by the researcher as an innovation and alternative solution to linear equations involving consecutive number problems in Algebra. It also aimed to contribute to the dearth of existing knowledge regarding innovative teaching in Mathematics which caters the needs of learners in this day and age.

Thus, this study finds meaning and significance.

\section{Methodology}

This study utilized evaluation research. Evaluation research focuses on assessing a particular practice or intervention at a given site. Its main purpose is to evaluate the usefulness of interventions such as new treatment methods or innovations in the real world. It is concluded that evaluation research is a systematic process that involves collecting data about organizations, processes, programs, services and/or resources. Evaluation research should enhance knowledge and 
decision making and lead to practical applications [7].

The comprehensible technique (CT) introduced by the researcher was the innovation that was evaluated by 20 respondents in this study. They were chosen purposively based on the following criteria: all have taken and studied Algebra, came from various age and professions and are willing to hear and evaluate the topics regarding consecutive number problems that will be discussed by the researcher within 25 to 30 minutes.

The researcher first presented the traditional solutions to consecutive number problems to each of the respondent, then the comprehensible technique (CT) was introduced. Subsequently, the respondents were requested to fill out a Likert-scale questionnaire to rate the technique's effectiveness and they were asked to give reflections on the open-ended questions regarding the importance of CT based on their actual experiences.

Weighted mean was utilized to compute for the effectiveness of the CT while transcription was done to analyze and summarize the comments given by the respondents.

The data gathering occurred from November 6 to 24, 2017.

\section{Discussion}

Topic: Solving Consecutive Number Problems using Linear Equation and Comprehensible Technique (CT)

CASE A. Solving for the missing consecutive integers (for odd number of missing integers i.e. 3 or 5 or 7 or...).

Example 1. The sum of three consecutive integers is 105 . Find the three consecutive integers.

Solution a. Using Linear Equation

Let $x$ be the $1^{\text {st }}$ integer

$x+1$ be the $2^{\text {nd }}$ integer

$x+2$ be the $3^{\text {rd }}$ integer

then,

$$
\begin{gathered}
x+x+1+x+2=105 \\
3 x+3=105 \\
3 x=105-3 \\
3 x=102 \\
x=\frac{102}{3}
\end{gathered}
$$

$x=341^{\text {st }}$ integer

$x+1=352^{\text {nd }}$ integer

$x+2=36 \quad 3^{\text {rd }}$ integer

Solution b. Using the Comprehensible Technique [8]

Since the sum of 3 consecutive integers is 105 . Just divide 105 to the number of consecutive integers which is 3 to obtain the middle number. 
$\frac{105}{3}=35$, thus, 35 is the middle number of the three consecutive integers.

Therefore, 34, 35 and 36 are the consecutive integers whose sum is 105.

Example 2. Find the five consecutive integers whose sum is 135 .

Solution a. Using Linear Equation

Let $x$ be the $1^{\text {st }}$ integer

$x+1$ be the $2^{\text {nd }}$ integer

$x+2$ be the $3^{\text {rd }}$ integer

$x+3$ be the $4^{\text {th }}$ integer

$x+4$ be the $5^{\text {th }}$ integer

then,

$$
\begin{gathered}
x+x+1+x+2+x+3+x+4=135 \\
5 x+10=135 \\
5 x=135-10 \\
5 x=125 \\
x=\frac{125}{5}
\end{gathered}
$$

$\begin{array}{ll}x=25 \quad 1^{\text {st }} & \text { integer } \\ x+1=26 & 2^{\text {nd }} \text { integer } \\ x+2=27 & 3^{\text {rd }} \text { integer } \\ x+3=28 & 4^{\text {th }} \text { integer } \\ x+4=29 & 5^{\text {th }} \text { integer }\end{array}$

Solution b. Using the Comprehensible Technique

$\frac{135}{5}=27,27$ is the middle number of the five consecutive integers.

Therefore, 25, 26, 27, 28 and 29 are the consecutive integers whose sum is 135.

CASE B. Solving for the missing consecutive odd or even integers (for odd number of missing even integers i.e.3 or 5 or 7 or...).

Example 1. The sum of 3 consecutive even integers is 252. Find the numbers.

Solution a. Using Linear Equation

Let $x=$ be the $1^{\text {st }}$ even integer

$x+2=$ be the $2^{\text {nd }}$ even integer

$x+4=$ be the $3^{\text {rd }}$ even integer

then,

$$
\begin{gathered}
x+x+2+x+4=252 \\
3 x+6=252 \\
3 x=252-6 \\
3 x=246 \\
x=\frac{246}{3}
\end{gathered}
$$

$x=82 \quad 1^{\text {st }}$ even integer 
$x+2=84 \quad 2^{\text {nd }}$ even integer

$x+4=86 \quad 3^{\text {rd }}$ even integer

Solution b. Using the Comprehensible Technique

$\frac{252}{3}=84,84$ is the middle number of the 3 consecutive even integers.

Therefore, 82, 84, 86 are the consecutive even integers whose sum is 252 .

Example 2. The sum of 7 consecutive odd integers is 105. Find the integers.

Solution a. Using Linear Equation

Let $x$ be the $1^{\text {st }}$ odd integer

$x+2$ be the $2^{\text {nd }}$ odd integer

$x+4$ be the $3^{\text {rd }}$ odd integer

$x+6$ be the $4^{\text {th }}$ odd integer

$x+8$ be the $5^{\text {th }}$ odd integer

$x+10$ be the $6^{\text {th }}$ odd integer

$x+12$ be the $7^{\text {th }}$ odd integer

then,

$$
\begin{gathered}
x+x+2+x+4+x+6+x+8+x+10+x+12=105 \\
7 x+42=105 \\
7 x=105-42 \\
7 x=63 \\
x=\frac{63}{7}
\end{gathered}
$$

$x=9 \quad 1^{\text {st }}$ odd integer

$x+2=112^{\text {nd }}$ odd integer

$x+4=13 \quad 3^{\text {rd }}$ odd integer

$x+6=15 \quad 4^{\text {th }}$ odd integer

$x+8=17 \quad 5^{\text {th }}$ odd integer

$x+10=196^{\text {th }}$ odd integer

$x+12=217^{\text {th }}$ odd integer

Solution b. Using the Comprehensible Technique

$\frac{105}{7}=15,15$ is the middle odd number of the seven consecutive odd integers.

Therefore, $9,11,13,15,17,19,21$ are the seven consecutive odd integers whose sum is 105 .

CASE C. Special Case (Solving for the missing consecutive integers -for even number of missing integers i.e. 2 or 4 or 6 or...).

Example number 1 . The sum of 4 consecutive integers is 66 . Find the integers.

Solution a. Using Linear Equation

Let $x$ be the $1^{\text {st }}$ integer

$x+1$ be the $2^{\text {nd }}$ integer

$x+2$ be the $3^{\text {rd }}$ integer 
$x+3$ be the $4^{\text {th }}$ integer

then,

$$
\begin{gathered}
x+x+1+x+2+x+3=66 \\
4 x+6=66 \\
4 x=66-6 \\
4 x=60 \\
x=\frac{60}{4}
\end{gathered}
$$

$$
\begin{aligned}
& x=15 \quad 1^{\text {st }} \text { integer } \\
& x+1=16 \quad 2^{\text {nd }} \text { integer } \\
& x+2=17 \quad 3^{\text {rd }} \text { integer } \\
& x+3=18 \quad 4^{\text {th }} \text { integer } \\
& \text { Solution } b . \text { Using the Comprehensible Technique }
\end{aligned}
$$

This problem belongs to the special case since the number of integers missing is 4 (even).

$\frac{66}{4}=16.5,16.5$ is the middle number of 16 and 17 and therefore 16 and 17 will be the middle numbers of the 4 consecutive integers, thus, the consecutive integers are 15, 16, 17, and 18 and their sum is 66 .

Example 2. The sum of 6 consecutive even integers is 150. Find the integers.

Solution a. Using Linear Equation

Let $x$ be the $1^{\text {st }}$ even integer

$x+2$ be the $2^{\text {nd }}$ even integer

$x+4$ be the $3^{\text {rd }}$ even integer

$x+6$ be the $4^{\text {th }}$ even integer

$x+8$ be the $5^{\text {th }}$ even integer

$x+10$ be the $6^{\text {th }}$ even integer

then,

$$
\begin{gathered}
x+x+2+x+4+x+6+x+8+x+10=150 \\
6 x+30=150 \\
6 x=150-30 \\
6 x=120 \\
x=\frac{120}{6}
\end{gathered}
$$

$x=20 \quad 1^{\text {st }}$ even integer

$x+2=222^{\text {nd }}$ even integer

$x+4=24 \quad 3^{\text {rd }}$ even integer

$x+6=26 \quad 4^{\text {th }}$ even integer

$x+8=28 \quad 5^{\text {th }}$ even integer

$x+10=30 \quad 6^{\text {th }}$ even integer

Solution b. Using the Comprehensible Technique 
$\frac{150}{6}=25,25$ is the middle number of 24 and 26 and therefore 24 and 26 will be the middle numbers of the 6 consecutive even integers, thus, the consecutive even integers are 20,22, 24, 26, 28 and 30 and their sum is 150 .

*Other applications of the Comprehensible Technique (Inverse Approach).

Example number 1. Find the sum of the numbers 5, 6, 7, 8 and 9.

To get the sum, the solution is just to multiply the middle number by the number of consecutive numbers.

So, the sum will be, 7 (middle number) $\times 5$ (number of consecutive numbers) $=35$.

Example number 2. Find the sum of the integers 4, 6, 8, 10, 12, 14, 16.

So, the sum will be, 10 (middle integer) $\times 7$ (number of consecutive integers) $=70$.

\section{Results}

\subsection{Effectiveness of the Comprehensible Technique}

Table 1 shows the rating of the effectiveness of the respondents to the comprehensible technique (CT) introduced by the researcher. It can be noted on the table that the respondents strongly agreed that the $\mathrm{CT}$ was very effective $(\mathrm{OWM}=$ 4.62). They particularly indicated that it is very effective in unlocking difficulties in solving consecutive number problems $(\mathrm{WM}=4.85)$. Furthermore, they rated the technique as easy to use ( $\mathrm{WM}=4.85)$, it is direct and simple $(\mathrm{WM}=4.75)$ and it's engaging and enjoyable $(\mathrm{WM}=4.70)$.

This implies that the CT is an excellent alternative solution in solving consecutive Table 1. Effectiveness of the comprehensible technique.

\begin{tabular}{lcc}
\hline & $\begin{array}{c}\text { Weighted } \\
\text { Mean }\end{array}$ & $\begin{array}{c}\text { Verbal } \\
\text { Description }\end{array}$ \\
\hline 1) The technique is engaging and enjoyable. & 4.70 & SA/VE \\
2) The technique is innovative and creative. & 4.45 & SA/VE \\
3) The technique is timely and relevant. & 4.60 & SA/VE \\
4) The technique is applicable to any types of learner. & 4.40 & SA/VE \\
5) The technique can motivate the learner to study Mathematics. & 4.65 & SA/VE \\
6) The technique is easy to use. & 4.85 & SA/VE \\
7) The technique is useful to the learner who does not like Mathematics. & 4.45 & SA/VE \\
8) The technique is meaningful to the learner. & 4.50 & SA/VE \\
9) The technique unlocks difficulties in solving consecutive number problems. & 4.85 & SA/VE \\
10) The technique is direct and simple. & 4.75 & SA/VE \\
Overall Weighted Mean & 4.62 & SA/VE \\
\hline
\end{tabular}

Legend: 1.00 to 1.79 Strongly Disagree-SD (The technique is worst); 1.80 to 2.59 Disagree-D (The technique is not effective); 2.60 to 3.39 Moderately Agree-MA (The technique is moderately effective); 3.40 to 4.19 Agree-A (The technique is effective); 4.20 to 5.00 Strongly Agree-SA (The technique is very effective). 
number problems in Algebra owing the fact that it deciphers problems in straightforward but enjoyable and engaging manner. This further implies that the technique can be used for checking the answers to the problems solved by linear equation.

\subsection{Reflections and Reactions Regarding the Comprehensible Technique}

The following are the comments given by the 20 respondents regarding the technique.

R1: "The technique introduced by the researcher will motivate the learners who do not like Algebra. In my case as an English teacher, I am afraid when I solve $x$ and $y$ but after encountering this technique, I became intrigued about studying Algebra. Teachers should invent easy ways of solving difficult problems in Mathematics for the benefit of those who are not Mathematically inclined (like me)-for us to learn Math in easy but effective way".

R2: "The technique reveals the easy way to solve a problem and it is very useful and effective".

R3: "It is easier than the traditional solution".

R4: "Finding out the answer with the use of much easier technique, such as this one, gave a great help to a student like me. It is good to know that there is a shorter and easier way to understand and solve number problems".

R5: "With the use of the technique suggested by the researcher, a student who will use the technique will not get confused especially when he/she sees letter $x$ and $y$.

R6: With the technique, it will be useful and effective to use compared to the long method of solving the problem".

R7: "This technique suggested by the researcher gave us another way to make things easier. It also proved that this method can be of help to those who find solving equation difficult especially different equations under Algebra”.

R8: "The suggested technique was more comprehensible and easier to understand. It only requires a little amount of time to solve a particular equation. It is a shortcut method and can be used by students who will join Mathematics quiz bee".

R9: "The technique is very easy to follow and very enjoyable even for young ones like me".

R10: "I believe the technique is comprehensible and it implies that there is always an easier and efficient way to solve Math problems. It takes some logical mind and openness to look at problems from different perspective".

R11: "The technique is meaningful and easy to use. This unlocks difficulties in solving consecutive number problems".

R12: "The technique is a very good alternative in solving linear equations involving consecutive integers. This can also be utilized to easily check the answer if the students used the long method using variables".

R13: "The technique is applicable and effective even to senior citizen like me 
because it is direct, simple and easy to follow".

R14: "For me, as a Civil Engineering student, it is very helpful especially for solving sophisticated math problems in a short time span. Actually, I am not aware with this kind of theorem or technique before, so now this will be a big help for me in solving algebraic equations easily with speed and accuracy. PS: This will be a big help for my licensure board exam in the future".

R15: "This technique is not just simple but also productive. We all know that most students do not like Math not only just because of numbers but also because of the letters they encounter when they are solving different equations. This technique does not require the students to deal with variables, hence, it will be easier for them to deal with this kind of problem without any difficulty".

R16: "Although the lesson is rarely used in my course as an English Major, the technique is creative and simple. It lets the students engage in Math when it comes to such topic. Complicated things are done simply without consuming a lot of time in solving, which is a helpful one in times of examinations especially board exams".

R17: "Before, solving consecutive integers is difficult for me because it takes much of my time and I don't know where to start. However, when I studied the suggested technique by the researcher it built my confidence in answering math problems. The technique is timely, easy to learn, can build enthusiasm to the learners and love for the subject".

R18: "The technique is very comprehensible, simple and easy to use".

R19: "The technique is very easy to follow and very easy to apply".

R20: " $A$ s I've done reading and comprehending the technique, I found it necessary and useful to the students whom find it difficult to understand mathematics especially consecutive number problem. I, myself, who took a six math subjects in my whole college life did not discover this technique. If students will have a chance to use this technique and discover more, this will probably help them to conquer and eliminate the mindset of many that mathematics is difficult. This technique may maximize the time of students in solving math problems and it also gives confidence to the students knowing that they can answer the problem correctly without hesitation by following the technique. By simply using techniques in solving mathematics, those stereotyping about this subject will diminish little by little".

Based on the transcriptions of the responses provided by the respondents, the CT was proven easy, direct and simple way of solving consecutive number problems in Algebra. It is very effective and efficient technique compared with the long method. Likewise, it is very useful and helpful to a person who will compete in Math Competitions and who will take board exams where time is of the essence since the $\mathrm{CT}$ involves and develops mental calculation.

Mental calculation comprises arithmetical calculations using only the human brain, with no help from any supplies or devices such as a calculator. People use mental calculation when computing tools are not available, when it is faster than 
other means of calculation (such as conventional educational institution methods), or even in a competitive context. Mental calculation often involves the use of specific techniques devised for specific types of problems [9] as in the case of $\mathrm{CT}$ where the specific problem that it caters is the consecutive number problems of Algebra.

\section{Conclusions and Recommendations}

The study explored and analyzed the comprehensible technique (CT) as an alternative and easy way in solving consecutive number problems in Algebra. The $\mathrm{CT}$ is an excellent method in performing consecutive number problems. It helps the learner to solve problems and find correct answers directly and easily within a short period of time. It eliminates the process of using the variable " $\mathrm{x}$ " and all the rules involved in performing linear equation since it only uses basic arithmetic and mental calculations. Further, because of the CT's efficiency, it can be utilized as shortcut way of solving consecutive number problems when competing in Math quiz bees or taking board examinations where time is of the essence.

Based on the conclusions, it is recommended that the author should share the CT to his colleagues, other Mathematics professors and engineers for a wider dissemination and exploration of the technique. They may share this to their students and may take initiative in trying to develop techniques that will serve as alternative solutions in dealing with complex Mathematical problems to cater the needs of those learners who are not mathematically inclined and for the benefits of those who love Mathematics.

\section{Acknowledgements}

The author would like to express his gratitude to his respondents for participating in this study. He is also grateful to his colleagues, Dr. Arneil G. Gabriel and Dr. Salvador A. Loria, for their assistance and comments that greatly improved this paper.

\section{References}

[1] Boiser, D. (2000) Strategies for Teaching: A Modular Approach. Rex Book Store: C.M. Recto Avenue, Manila.

[2] Crockett, L. (2015) Seven Characteristics of an Innovative Educator. Global Digital Citizen Foundation.

[3] Yeoh, M. (2015) What Is Innovative Teaching? RMIT University. https://www.researchgate.net/post/What_is_innovative_teaching

[4] Thwaites, G.N. (1982) Why Do Children Find Algebra Difficult? Mathematics in School, Oakman School, 16-17.

[5] Garlikov, R. (n.d.) Understanding Algebra. The Way Algebra Works. http://www.garlikov.com/math/UnderstandingAlgebra.html.

[6] Kibria, G. (2015) What Is Innovative Teaching? SEAMEO RECSAM. https://www.researchgate.net/post/What_is_innovative_teaching

[7] Powell, R. (2006) Evaluation Research: An Overview. Library Trends, 55, 102-120. 
https://doi.org/10.1353/lib.2006.0050

[8] Subia, G. (2006) Development of an Instructional Manual in College Algebra for Nursing Students. Instructional Resource Center, WUP, Cabanatuan City, 170-174.

[9] Wikepedia (2007, February) Mental Calculation.

https://en.wikipedia.org/wiki/Mental_calculation 